\title{
COMPARING THE OPERATIVE DURATION AND THE PAIN SCORES IN PATIENTS UNDERGOING SINGLE PORT LAPAROSCOPIC CHOLECYSTECTOMY (SPLC) VS. MULTIPLE PORT LAPAROSCOPIC CHOLECYSTECTOMY (MPLC)
}

\author{
Neeraj Kumar Banoria1, Shaily Panwar², Surya Prakash³, Santosh Kumar', Shiva Kumar 5 \\ ${ }^{1}$ Assistant Professor, Department of Surgery, Maharani Laxmi Bai Medical College, Jhansi. \\ ${ }^{2}$ Senior Resident, Department of Radiology, Maharani Laxmi Bai Medical College, Jhansi. \\ ${ }^{3}$ Associate Professor, Department of Surgery, Maharani Laxmi Bai Medical College, Jhansi. \\ 4 Senior Resident, Department of Surgery, Maharani Laxmi Bai Medical College, Jhansi. \\ 5Junior Resident, Department of Surgery, Maharani Laxmi Bai Medical College, Jhansi.
}

\begin{tabular}{l}
\hline ABSTRACT \\
BACKGROUND \\
Comparing the operative duration and the pain scores in patients undergoing Single Port Laparoscopic Cholecystectomy (SPLC) \\
vs. multiple port laparoscopic cholecystectomy (MPLC).
\end{tabular}

\section{MATERIALS AND METHODS}

In this comparative randomised study, 100 patients diagnosed as having gall stones, who fit into the inclusion criteria; 50 patients were included in the single port laparoscopic cholecystectomy (SPLC) Group and 50 Multiple Port Laparoscopic Cholecystectomy (MPLC) Group.

\section{RESULTS}

Out of 50 patients operated by SPLC, 13 were males and 37 were females with mean age of $38.62 \pm 12.56$ years. In the MPLC group distribution was 9 males and 41 females in a total of 50 patients and the mean age was $37.86 \pm 11.31$ years. Mean operative time in SPLC group was significantly higher than the MPLC group. Mean VAS pain score at 12, 24, 36 and 48 hrs. was significantly lower in SPLC group as compared to MPLC group; which was significant at all times. Mean NRS pain score at 12, 24, 36 and 48 hrs. was lower in SPLC group as compared to MPLC group; which was significant at 24 and 48 hrs., but not significant at 12 and 36 hrs. Mean VDS pain score at 12, 24, 36 and 48 hrs. was significantly lower in SPLC group as compared to MPLC group, which was significant at all times. Mean FPS pain score at 12, 24, 36 and 48 hrs. was lower in SPLC group as compared to MPLC group, which was significant at 12,24 and $36 \mathrm{hrs}$. but not significant at $48 \mathrm{hrs}$.

\section{CONCLUSION}

In early post-operative hours, VAS and VDS scores were lower in SPLC than MPLC which was significant all the time, but NRS and FPS scores were not significant in all the early hours in spite of higher operative time in SPLC.

\section{KEYWORDS}

Single Port Laparoscopic Cholecystectomy, Multiple Port Laparoscopic Cholecystectomy, VAS Score, VDS Score, NRS Score, FPS Score, Post-Operative Relief, Operative Time.

HOW TO CITE THIS ARTICLE: Banoria NK, Panwar S, Prakash S, et al. Comparing the operative duration and the pain scores in patients undergoing single port laparoscopic cholecystectomy (SPLC) vs. multiple port laparoscopic cholecystectomy (MPLC). J. Evolution Med. Dent. Sci. 2016;5(75):5568-5572, DOI: 10.14260/jemds/2016/1258

\section{INTRODUCTION}

Cholelithiasis is found in a large number of people, though asymptomatic. Worldwide occurrence of gallstones varies from 6-20\%.[1] Asymptomatic gallstone patients develop complications at an annual rate of 1-2\%.[2] Laparoscopic Cholecystectomy (LC) was first undertaken by Philippe Mouret in France in 1987[3] and today laparoscopic cholecystectomy is the gold standard in the management of symptomatic gall bladder stones, the benefits conferred by Minimal Access Surgery (MAS) include reduced post-operative

Financial or Other, Competing Interest: None.

Submission 10-08-2016, Peer Review 31-08-2016,

Acceptance 09-09-2016, Published 19-09-2016.

Corresponding Author:

Dr. Neeraj Kumar Banoria,

PR-17, Doctor Campus,

Maharani Laxmi Bai Medical College,

Jhansi, Uttar Pradesh.

E-mail: drnkb2000@gmail.com

DOI: $10.14260 /$ jemds/2016/1258 pain, decreased hospital stay, less scaring and few incisions.(4) In the quest for making MAS more patient friendly in terms of better cosmesis and reduced post-operative pain, Single Port Laparoscopic Cholecystectomy (SPLC) has emerged as a novel technique. Navarra et al (1997) ${ }^{[5]}$ were the first to perform SPLC, demonstrating its technical feasibility and suggesting that it may prove advantageous in selected patients.

Nowadays, traditional Multiport Laparoscopic Cholecystectomy (MPLC) eventually has emerged as the most widely performed laparoscopic procedure. We are again at crossroads where surgeons are re-examining a gold standard procedure in the face of a surgical innovation. For any new technique to offer the safety and feasibility of the previously available technique as well as has potential to confer further benefits. To examine the pain scores, we conducted a prospective and comparative cohort study between two groups of patients who underwent SPLC and MPLC.

\section{AIMS AND OBJECTIVES}

Study to compare the operative duration and post-operative 
pain after Laparoscopic cholecystectomies done by Single Port vs. Multiple Port.

\section{MATERIAL AND METHODS}

This comparative randomised study was conducted in Department of Surgery, M.L.B. Medical College, Jhansi, from 01.01.14 to $30.06 .15 ; 100$ consecutive patients who fit into the inclusion criteria were included in the study; 50 patients were included in the Single Port Laparoscopic Cholecystectomy (SPLC) Group and 50 Multiple Port Laparoscopic Cholecystectomy (MPLC) Group. An informed consent was taken from all patients before enrolment in the study.

The inclusion criteria were age of patient between 15 and 75 years and diagnosis of chronic/acute cholecystitis, symptomatic cholelithiasis, Gall Bladder (GB) polyp, GB Sludge, empyema, mucocele. The exclusion criteria were severe comorbid conditions (uncontrolled diabetes, hypertension, severe direct hyperbilirubinaemia) and ASA Grade 4.

The technique of Multiple Port Laparoscopic Cholecystectomy (MPLC) was performed using a four-trocar approach in routine cases, Single Port Laparoscopic Cholecystectomy (SPLC) has been performed using single umbilical incision.

All operations were performed by experienced surgeons and data for the study were prospectively collected and recorded on Microsoft Excel(R) worksheet.

\section{RESULTS}

\begin{tabular}{|c|c|c|}
\hline $\begin{array}{c}\text { Age } \\
\text { (Yrs.) }\end{array}$ & $\begin{array}{c}\text { No. of Patients } \\
\text { (MPLC) (\%) }\end{array}$ & $\begin{array}{c}\text { No. of Patients } \\
\text { (SPLC) (\%) }\end{array}$ \\
\hline $1-10$ & $0(0 \%)$ & $0(0 \%)$ \\
\hline $11-20$ & $2(4 \%)$ & $1(2 \%)$ \\
\hline $21-30$ & $15(30 \%)$ & $16(32 \%)$ \\
\hline $31-40$ & $17(34 \%)$ & $15(30 \%)$ \\
\hline $41-50$ & $11(22 \%)$ & $10(20 \%)$ \\
\hline $51-60$ & $3(6 \%)$ & $6(12 \%)$ \\
\hline$>60$ & $2(4 \%)$ & $2(4 \%)$ \\
\hline Total & $\mathbf{5 0 ( 1 0 0 \% )}$ & $\mathbf{5 0}(\mathbf{1 0 0} \%)$ \\
\hline \multicolumn{2}{|c|}{ Table 1: Age Wise Distribution (MPLC \& SPLC) } \\
\hline
\end{tabular}

\begin{tabular}{|c|c|c|c|}
\hline \multirow{2}{*}{ Parameter } & SPLC & MPLC & \multirow{2}{*}{ P Value } \\
\cline { 2 - 4 } & $\begin{array}{c}\text { Mean } \pm \text { SD } \\
\mathbf{( n = 5 0 )}\end{array}$ & $\begin{array}{c}\text { Mean } \pm \text { SD } \\
\mathbf{( n = 5 0 )}\end{array}$ & \\
\hline Age (Yrs.) & $38.62 \pm 12.66$ & $37.86 \pm 11.31$ & $\begin{array}{c}0.3789 \\
\text { (Not } \\
\text { Significant) }\end{array}$ \\
\hline
\end{tabular}

Table 2: Comparison of Age in Study Groups

\begin{tabular}{|c|c|c|}
\hline Sex & $\begin{array}{c}\text { No. of Patients } \\
\text { (Percentage) } \\
\text { (SPLC) }\end{array}$ & $\begin{array}{c}\text { No. of Patients } \\
\text { (Percentage) } \\
\text { (MPLC) }\end{array}$ \\
\hline Female & $37(74 \%)$ & $41(82 \%)$ \\
\hline Male & $13(26 \%)$ & $9(18 \%)$ \\
\hline Total & $\mathbf{5 0}(100 \%)$ & $\mathbf{5 0}(100 \%)$ \\
\hline \multicolumn{2}{|r|}{ Table 3: Sex Wise Distribution (In SPLC \& MPLC) } \\
\hline
\end{tabular}

\begin{tabular}{|c|c|c|}
\hline $\begin{array}{c}\text { SPLC } \\
(\mathbf{5 0 )}\end{array}$ & $\begin{array}{c}\text { MPLC } \\
(\mathbf{5 0 )}\end{array}$ & P Value \\
\hline $24.9 \pm 9.00$ & $19.32 \pm 7.36$ & $0.0004(\mathrm{~S})$ \\
\hline \multicolumn{3}{|c|}{ Table 4: Comparison of the Mean of Operative Time in } \\
the SILC and BSLC \\
\hline
\end{tabular}

\begin{tabular}{|c|c|c|c|c|}
\hline & 12 Hrs. & 24 Hrs. & 36 Hrs. & 48 Hrs. \\
\hline SILC & $4.58 \pm$ & $3.92 \pm$ & $3.28 \pm$ & $2.69 \pm$ \\
(50) & 0.6105 & 0.5970 & 0.5168 & 0.4062 \\
\hline SLC & $5.16 \pm$ & $4.56 \pm$ & $3.8 \pm$ & $3.14 \pm$ \\
(50) & 0.9234 & 0.9304 & 0.7764 & 0.6854 \\
\hline P Value & $\mathbf{0 . 0 0 0 4}$ & $\mathbf{0 . 0 0 0 1}$ & $\mathbf{0 . 0 0 0 2}$ & $\mathbf{0 . 0 0 0 3}$ \\
& (S) & (S) & (S) & (S) \\
\hline Table 5: Comparison of the Mean of Pain Score of Visual \\
Analogue Scale (VAS) in the SPLC \& MPLC \\
\hline
\end{tabular}

\begin{tabular}{|c|c|c|c|c|}
\hline & 12 Hrs. & 24 Hrs. & 36 Hrs. & 48 Hrs. \\
\hline SILC & $5.24 \pm$ & $4.1 \pm$ & $3.26 \pm$ & $2.8 \pm$ \\
(50) & 0.4314 & 0.7071 & 0.4430 & 0.5345 \\
\hline \multirow{2}{*}{ SLC (50) } & $5.36 \pm$ & $4.62 \pm$ & $3.76 \pm$ & $3.08 \pm$ \\
& 0.7494 & 0.7253 & 0.7439 & 0.5656 \\
\hline \multirow{2}{*}{ P Value } & $\mathbf{0 . 3 2 8 9}$ & $\mathbf{0 . 0 0 0 5}$ & $\mathbf{0 . 9 9 9 6}$ & $\mathbf{0 . 0 1 2 5}$ \\
& (NS) & (S) & (NS) & (S) \\
\hline
\end{tabular}

Table 6: Comparison of the Mean of Pain Score of Numeric Response Scale (NRS) in the SPLC \& MPLC

\begin{tabular}{|c|c|c|c|c|}
\hline & 12 Hrs. & 24 Hrs. & 36 Hrs. & 48 Hrs. \\
\hline SILC & $3.38 \pm$ & $3.1 \pm$ & $2.32 \pm$ & $1.92 \pm$ \\
$(50)$ & 0.6023 & 0.5439 & 0.6527 & 0.6006 \\
\hline \multirow{2}{*}{ SLC (50) } & $3.76 \pm$ & $3.48 \pm$ & $2.78 \pm$ & $2.44 \pm$ \\
& 0.7439 & 0.6773 & 0.8919 & 0.9071 \\
\hline \multirow{2}{*}{ P Value } & $\mathbf{0 . 0 0 6 0}$ & $\mathbf{0 . 0 0 2 6}$ & $\mathbf{0 . 0 0 4 1}$ & $\mathbf{0 . 0 0 1 0}$ \\
& (S) & (S) & (S) & (S) \\
\hline
\end{tabular}

Table 7: Comparison of the Mean of Pain Score of Verbal Descriptor Scale (VDS) in the SPLC \& MPLC

\begin{tabular}{|c|c|c|c|c|}
\hline & 12 Hrs. & 24 Hrs. & 36 Hrs. & 48 Hrs. \\
\hline SILC & $5.26 \pm$ & $3.88 \pm$ & $2.84 \pm$ & $1.76 \pm$ \\
$(50)$ & 0.9648 & 0.4797 & 0.9913 & 0.7708 \\
\hline \multirow{2}{*}{ SLC (50) } & $5.88 \pm$ & $4.6 \pm$ & $3.72 \pm$ & $3 \pm$ \\
& 0.7461 & 0.9258 & 0.9905 & 1.0879 \\
\hline \multirow{2}{*}{ P Value } & $\mathbf{0 . 0 0 0 5}$ & $\mathbf{0 . 0 0 0 1}$ & $\mathbf{0 . 0 0 0 1}$ & $\mathbf{0 . 9 9 2 1}$ \\
& (S) & (S) & (S) & (NS) \\
\hline \multicolumn{5}{|c|}{ Table 8: Comparison of the Mean of Faces Pain Scale } \\
(FPS) in the SPLC \& MPLC \\
\hline
\end{tabular}

\section{DISCUSSION}

Out of 50 patients operated by SPLC, 13 were males and 37 were females. In the MPLC group, distribution was 9 males and 41 females. Majority of patients were in 20-40 years' age group (62\% in SPLC vs 64\% in MPLC). The mean age of patients in SPLC group was $38.62 \pm 12.56$ years and in MPLC group was $37.86 \pm 11.31$ years and there is no significant difference between the mean age of two groups (Table 1). 


\begin{tabular}{|c|c|c|c|c|}
\hline & \multirow[t]{2}{*}{ Age (Yrs.) } & \multicolumn{2}{|c|}{$\operatorname{Sex}(\%)$} \\
\hline & & & Male & Female \\
\hline \multirow{3}{*}{$\begin{array}{l}\text { Our } \\
\text { Study }\end{array}$} & Total & $38.24 \pm 11.95$ & 22 & 78 \\
\hline & SILC & $38.62 \pm 12.56$ & 13 & 37 \\
\hline & SLC & $37.86 \pm 11.31$ & 9 & 41 \\
\hline \multicolumn{2}{|c|}{$\begin{array}{c}\text { Hodgett, } \\
\text { et al (2009)[6] }\end{array}$} & 50 (median) & 20.6 & 79.3 \\
\hline \multicolumn{2}{|c|}{$\begin{array}{c}\text { Rao PP, } \\
\text { et al (2008) }{ }^{[7]}\end{array}$} & 23-67 (range) & 20 & 80 \\
\hline \multicolumn{2}{|c|}{$\begin{array}{c}\text { Lee, } \\
\text { et al }(2009)^{[8]}\end{array}$} & $\begin{array}{l}47.5 \pm 12.2 \\
\text { (mean) }\end{array}$ & 35.1 & 64.8 \\
\hline \multicolumn{5}{|c|}{$\begin{array}{c}\text { Table 9: Comparison of Age and Sex Distribution with } \\
\text { other Studies }\end{array}$} \\
\hline
\end{tabular}

Like most other studies showing female preponderance (Table 3), our study also shows significant female preponderance. In our study, mean operative time in SPLC group was higher $(24.9+9$ minute $)$ than the MPLC group (19.32+7.36 minute), which was significant (Table 4). Operative time was reported in four RCTs, two studies reporting a longer operative time in the SPLC group (Phillips et al 2011[9]; Tsimoyiannis et al 2010[10]), and two studies reporting no significant difference between the two groups (Cao et al 2011[11]; Lai et al 2011[12]). Cao et al (2011)[11] reported that operative time decreased considerably from 100 minutes for the first SPLC to less than 60 minutes after the fifth operation, then stabilised to approximately 50 minutes. Prasad et al (2011) ${ }^{[13]}$ reported that the mean operative time for the first 50 SPLC cases (79.2 minutes) was significantly higher when compared to the operative time for the second 50 cases $(54.32$ minutes) $(\mathrm{P}<0.05)$. In the case series by Ersin et al (2010),[14] 24 the duration of surgery for single port cholecystectomy ranges from 105-110 mins. with a mean of 94 mins. Prospective randomised study by Deveci U. et $\mathrm{al}(2010)^{[15]}$ concluded that operating time was significantly longer in SPLS group as compared with MPCL group (73 minutes vs. 48 minutes; $\mathrm{P}<0.05)$. Culp et al[16] concluded that operative time was significantly longer in the SPLC group. An average of 65 minutes was needed to complete a SPLC (range 35-141) versus 51 minutes (range 24-109) for a MPLC $(\mathrm{P}<$ 0.001). Bucher $P$ et al (2011)[17] concluded that operating times and complications were similar in the two groups. Better pain profiles and lower analgesia requirements were recorded in the LESS group $(\mathrm{P}<0 \cdot 001)$. In our study the mean VAS pain score at 12, 24, 36 and $48 \mathrm{hrs}$. was significantly lower in SPLC group as compared to MPLC group, which was significant at all times. Postoperative pain was assessed in four RCTs.

Cao et al (2011) ${ }^{[11]}$ reported that mean VAS pain scores were not significantly different between the SPLC $(2.3 \pm 0.9)$ and MPLC $(2.6 \pm 1.2)$ groups $(\mathrm{P}=0.435)$ on the first postoperative day. Similarly, mean VAS pain scores were not significantly different between the SPLC $(1.3 \pm 0.7)$ and MPLC $(1.5 \pm 0.5)$ groups $(\mathrm{P}=0.417)$ on the third postoperative day. The study by Lai et al (2011) ${ }^{[12]}$ reported that median VAS pain scores were not significantly different between the SPLC (4.5, range $2-8)$ and MPLC (4.0, range $2-7)$ groups $(P=0.203)$ six hours after surgery; however, pain was significantly higher in the SPLC group (1, range 0-3) compared with the MPLC group $(0$, range $0-2)(\mathrm{P}=0.048)$ on the seventh postoperative day. Phillips et al (2011) ${ }^{[9]}$ reported that average VAS pain scores were higher in SPLC patients compared with MPLC patients at
3, 5 and 30 days after surgery; however, no significant differences between the groups were observed at any other time points. Despite the differences in pain scores, no significant differences in pain medication used between the two groups were observed immediately following surgery or at 1,3 or 5 days or 1 or 2 weeks after surgery. Tsimoyiannis et al (2010)[10] reported that abdominal pain was significantly higher in MPLC patients compared with SPLC patients at 12, 24, 48 and 72 hours after surgery, while shoulder pain was significantly higher in MPLC patients compared with SPLC patients at 6, 24, 48 and 72 hours after surgery.

Froghi et al (2011) ${ }^{[18]}$ reported that mean VAS pain scores six hours after surgery were not significantly different in the SPLC $(4.4 \pm 2.3)$ and MPLC $(5.1 \pm 2.7)$ groups $(\mathrm{P}=0.115)$ Similarly, mean VAS pain scores 24 hours after surgery were not significantly different in the SPLC $(2.8 \pm 2.1)$ and MPLC $(3.8 \pm 2.0)$ groups $(\mathrm{P}=1.0)$. At the 2 -week and 2 -month followup telephone interview, patients in both groups reported slight pain at the umbilical incision site. The study by Prasad et al (2011) ${ }^{[13]}$ reported that mean VAS pain scores eight hours after surgery were not significantly different in the SPLC (2.62) and MPLC (2.78) groups ( $\mathrm{P}=0.176)$. The mean VAS pain score for the first 50 SPLC cases (2.84) was significantly higher when compared to the mean pain score for the second 50 cases (2.58) $(\mathrm{P}=0.026)$. Vidal et al (2011) ${ }^{[19]}$ reported that the median VAS pain score one day after surgery was not significantly different in the SPLC group (3, range 1-5) compared with the MPLC group (4, range 1-8) $(\mathrm{P}=0.311)$. Madureira FA et al (2013) ${ }^{[20]}$ concluded that the mean VAS score for pain at hour 3 was 2.0 points (0-7) for the SPLC group and $4.0(0-10)$ for the MPLC group ( $p=0.07)$, and at postoperative hour 24 it was 0.3 points (0-6) for LESS and 2.3 (0-10) for LC $(\mathrm{p}=0.03)$. A randomised controlled study conducted by Mingwei Zheng et al (March 2012).[21] They concluded less pain score with SPLS as compared to conventional laparoscopic cholecystectomy.

Liangyuan Geng et al (Oct 2013)[22] also concluded SPLC was superior to MPLC in postoperative pain within $12 \mathrm{hrs}$. (VAS in 3-4 hrs., WMD $=-0.704, \mathrm{P}=0.026$; VAS in 6-8 hrs., $\mathrm{WMD}=-0.613, \mathrm{P}=0.010)$. MPLC was superior to SPLC in Operating Time (OT) $(\mathrm{WMD}=13.613, \mathrm{P}<0.001)$ and need of additional instruments $(\mathrm{OR}=7.448, \mathrm{P}<0.001)$. Similar results was conducted by Alberto Arezzo et al (July 2013)[23] and according to them visual analogue pain score at $24 \mathrm{hrs}$. after surgery was low in patients of SPLS in comparison with patients of MPCL. In a study by AbdEllatif M E et al (2013) ${ }^{[24]}$ concluded that SPLC patients have an improved pain profile at 4, 12 and 24 hrs. Asakuma M et al (2011) ${ }^{[25]}$ concluded that VAS score on day 1 after surgery was significantly less in the SPLC group than in the MPLC group: median (range) 24 (12$38)$ versus 45 (33-57) $\mathrm{mm}(\mathrm{P}=0.002)$. Significantly, fewer patients in the SPC group required analgesia ( 9 of 24 versus 19 of 25 in the LC group; $P=0 \cdot 007)$. A study by Bucher $P$ et al (2011) ${ }^{[15]}$ concluded better pain profiles and lower analgesia requirements were recorded in the SPLC group $(\mathrm{P}<0 \cdot 001)$. A randomised controlled trial by Chang SK et al (2015) ${ }^{[26]}$ concluded SPLC was non-inferior for pain at umbilical sites at rest and at extra-umbilical sites at all times. At 24 hours postoperatively, SPLC was associated with significantly less pain at extra-umbilical sites (rest: $\mathrm{P}=0.002$; movement: $\mathrm{P}=0.004$ ). Wong JS et al (2012) ${ }^{[27]}$ after using visual analog scale concluded that the postoperative pain score was 
significantly lower in the SPLC group $(2.9 \pm 1.6$ in SPLC group vs. $4.8 \pm 1.5$ in MPLC group ( $<<0.01)$. Deveci U. et al (2013) [15] concluded higher pain scores in SPLS group versus MPCL group in postoperative day $1(\mathrm{P}<0.05)$. A study conducted by Joseph SP et al (Sept 2011)[28] compared SPLS with the gold standard. No significant difference were noted in the pain score of both surgeries. Similar result was also found by Lee PC et al (2010)[8] in a randomised clinical trial of single incision laparoscopic cholecystectomy versus mini-laparoscopic cholecystectomy.

In our study, the mean NRS pain score at 12, 24, 36 and 48 hrs. was lower in SPLC group as compared to MPLC group. There was significant difference in the mean NRS pain score in SPLC group as compared to MPLC group at 24 and $48 \mathrm{hrs.}$, but no significant difference was found at 12 and $36 \mathrm{hrs}$. (Table 6). In our study, the mean VDS pain score at 12, 24, 36 and $48 \mathrm{hrs}$. was significantly lower in SPLC group as compared to SLC group, which was significant at all times (Table 7). In our study the mean FPS pain score at 12, 24, 36 and $48 \mathrm{hrs}$. was lower in SPLC group as compared to MPLC group. There was significant difference in the mean FPS pain score in SPLC group as compared to MPLC group at 12, 24 and 36 hrs., but no significant difference was found at $48 \mathrm{hrs}$. (Table 9). There is no study found in literature, which has compared postoperative pain in patients undergoing SPLC vs. MPLC on NRS, FPS and VDS scale.

\section{CONCLUSION}

Based on the comparative evidence presented in this study, the following conclusions were made:

1. Patients presenting to M.L.B. Medical College with gall stone diseases belong to significantly younger group and shows significant female preponderance.

2. Mean operative time in SPLC group was significantly higher than the MPLC group.

3. Mean VAS pain score at 12, 24, 36 and 48 hrs. was significantly lower in SPLC group as compared to MPLC group, which was significant at all times.

4. Mean NRS pain score at 12, 24, 36 and $48 \mathrm{hrs}$. was lower in SPLC group as compared to MPLC group, which was significant at 24 and 48 hrs. but not significant at 12 and $36 \mathrm{hrs}$.

5. Mean VDS pain score at 12, 24, 36 and 48 hrs. was significantly lower in SPLC group as compared to MPLC group, which was significant at all times.

6. Mean FPS pain score at 12, 24, 36 and $48 \mathrm{hrs}$. was lower in SPLC group as compared to MPLC group, which was significant at 12, 24 and 36 hrs. but not significant at 48 hrs.

\section{REFERENCES}

1. Chiang KW, Lee FM, Santen S. Cholelithiasis, emedicine online 2010.

2. Bona S, Monzani R, Romario FU, et al. Outpatient laparoscopic cholecystectomy: a prospective study of 250 patients. Gastroenterol Clin Biol 2007;31(11):1010-5.

3. Adachi T, Okamoto $\mathrm{T}$, Ono $\mathrm{S}$, et al. Technical progress in single-incision laparoscopic cholecystectomy in our initial experience. Minimally Invasive Surgery 2011;2011: 972647.

4. Vecchio R, MacFayden BV, Palazzo F. History of laproscopic surgery. Panminerva Med 2000;42(1):87-90.
5. Navarra G, Pozza E, Occhionorelli S, et al. One-wound laparoscopic cholecystectomy. British Journal of Surgery 1997;84(5):695.

6. Hodgett SE, Hernandez JM, Morton CA, et al. Laparoendoscopic single site (LESS) cholecystectomy. Journal of Gastrointestinal Surgery 2009;13(2):188-92.

7. Rao PP, Bhagawat SM, Rane A, et al. The feasibility of single port laproscopic cholecystectomy: a pilot study of 20 cases. HPB (Oxford) 2008;10(5):336-40.

8. Lee PC, Lo C, Lai PS, et al. Randomized clinical trial of single-incision laparoscopic cholecystectomy versus minilaparoscopic cholecystectomy. Br J Surg 2010;97(7): 1007-12.

9. Phillips MS, Marks JM, Roberts K, et al. Intermediate results of a prospective randomized controlled trial of traditional four-port laparoscopic cholecystectomy versus singleincision laparoscopic cholecystectomy. Surgical Endoscopy 2011;26(5):1296-303.

10. Tsimoyiannis EC, Tsimogiannis KE, Pappas-Gogos G, et al. Different pain scores in single transumbilical incision laparoscopic cholecystectomy versus classic laparoscopic cholecystectomy: a randomized controlled trial. Surgical Endoscopy 2010;24(8):1842-8.

11. Cao ZG, Cai W, Qin MF, et al. Randomized clinical trial of single-incision versus conventional laparoscopic cholecystectomy: short-term operative outcomes. Surgical Laparoscopy Endoscopy and Percutaneous Techniques 2011;21(5):311-3.

12. Lai EC, Yang GP, Tang CN, et al. Prospective randomized comparative study of single incision laparoscopic cholecystectomy versus conventional four-port laparoscopic cholecystectomy. The American Journal of Surgery 2011;202(3):254-8.

13. Prasad A, Mukherjee KA, Kaul S, et al. Postoperative pain after cholecystectomy: conventional laparoscopy versus single-incision laparoscopic surgery. Journal of Minimal Access Surgery 2011;7(1):24-7.

14. Ersin S, Firat O, Sozbilen M. Single incision laparoscopic cholecystectomy: is it more than a challenge? Surg Endosc 2010;24(1):68-71.

15. Deveci U, Barbaros U, Kapakli MS, et al. The comparison of single incision laparoscopic cholecystectomy and three port laparoscopic cholecystectomy: prospective randomized study. J Korean Surg Soc 2013;85(6):275-82.

16. Culp BL, Cedillo VE, Arnold DT. Single-incision laparoscopic cholecystectomy versus traditional four-port cholecystectomy. Proc Bayl Univ Med Cent 2012;25(4):319-23.

17. Bucher P, Pugin F, Buchs NC, et al. Randomized clinical trial of laparoendoscopic single-site versus conventional laparoscopic cholecystectomy. Br J Surg 2011; 98(12): 1695-702.

18. Froghi F, Sodergren MH, Wright VJ, et al. Single-center experience in systemic stress and short-term morbidity of single-incision cholecystectomy. Surgical Innovation 2011;19(2):117-22.

19. Vidal 0 , Valentini $M$, Ginestà $C$, et al. Laparoscopic singlesite surgery appendectomy. Surg Endosc 2010;24(3): 686-91. 
20. Madureira FA, Manso JE, Madureira Fo D, et al. Randomized clinical study for assessment of incision characteristics and pain associated with LESS versus laparoscopic cholecystectomy. Surg Endosc 2013;27(3): 1009-15.

21. Zheng M, Qin M, Zhao H. Laparoendoscopic single-site cholecystectomy: a randomized controlled study. Minim Invasive Ther Allied Technol 2012;21(2):113-7.

22. Geng L, Sun C, Bai J. Single incision versus conventional laparoscopic cholecystectomy outcomes: a meta-analysis of randomized controlled trials. PLoS ONE 2013; 8(10):e76530.

23. Arezzo A, Scozzari G, Famiglietti F, et al. Is single-incision laparoscopic cholecystectomy safe? Results of a systematic review and meta-analysis. Surg Endosc 2013;27(7): 2293-304.

24. Ellatif AME, Askar WA, Abbas AE, et al. Quality-of-life measures after single-access versus conventional laparoscopic cholecystectomy: a prospective randomized study. Surg Endosc 2013;27(6):1896-906.
25. Asakuma M, Hayashi M, Komeda K, et al. Impact of single port cholecystectomy on postoperative pain. Br J Surg 2011;98(7):991-5.

26. Chang SK, Wang YL, Shen L, et al. A randomized controlled trial comparing post-operative pain in single-incision laparoscopic cholecystectomy versus conventional laparoscopic cholecystectomy. World J Surg 2015;39(4): 897-904.

27. Wong JS, Cheung YS, Fong KW, et al. Comparison of postoperative pain between single-incision laparoscopic cholecystectomy and conventional laparoscopic cholecystectomy: prospective case-control study. Surg Laparosc Endosc Percutan Tech 2012;22(1):25-8.

28. Joseph SP, Moore BT, Slayden G, et al. Patient perception of single-incision laparoscopic cholecystectomy. JSLS 2013;17(4):585-95. 